\title{
Autoantibodies in Human Diabetic Depression Inhibit Adult Neural Progenitor Cells In vitro and Induce Depressive-Like Behavior in Rodents
}

\author{
Mark B. Zimering ${ }^{1,2 *}$, Joseph A. Behnke ${ }^{3}$, Smita Thakker-Varia ${ }^{3}$ and Janet Alder ${ }^{3}$ \\ ${ }^{1}$ Medical Service, Department of Veterans Affairs New Jersey Health Care System, Lyons, New Jersey, USA \\ ${ }^{2}$ Division of Endocrinology, Rutgers-Robert Wood Johnson Medical School, New Brunswick, New Jersey, USA \\ ${ }^{3}$ Department of Neuroscience and Cell Biology, Rutgers- Robert Wood Johnson Medical School, Piscataway, New Jersey, USA
}

Received: March 21, 2015; Accepted: April 17, 2015; Published: April 25, 2015

*Corresponding author: Mark B. Zimering, Division of Endocrinology, Rutgers- Robert Wood Johnson Medical School, New Brunswick, New Jersey, USA, Tel: 908 647-0180 x4426; Fax: 908 604-5249; Email: mark.zimering@va.gov

\begin{abstract}
Aim: Diabetic depression increases in association with microvascular complications. We tested a hypothesis that circulating autoantibodies having anti-endothelial and anti-neuronal properties increase in subsets of diabetes with co-morbid depression.

Methods: Protein-A eluates from plasma of 20 diabetic depression patients and 30 age-matched controls were tested for effects on endothelial cell survival, neurite outgrowth in rat pheochromocytoma (PC12) cells, or process extension and survival in adult rat dentate gyrus neural progenitor cells. The protein-A eluates from depressed or non-depressed, diabetic patients were injected (via intracerebroventricular route) into mice and 7-10 days later behavioral tests (sucrose preference, and tail suspension tests) were conducted to determine whether the autoantibodies induced anhedonia or despair.
\end{abstract}

Results: Diabetic depression $(\mathrm{n}=20)$ autoantibodies caused a significant inhibition of PC12 cell neurite outgrowth $(P<0.001)$ or endothelial cell proliferation compared to autoantibodies in control, diabetic $(n=20)$ or non-diabetic $(n=10)$ patients without depression. Process extension and survival in adult rat dentate gyrus neural progenitor cells was significantly reduced $(P<0.001)$ by diabetic depression autoantibodies $(\mathrm{n}=11)$ compared to the effects from similar concentrations $(5-7 \mu \mathrm{g} / \mathrm{mL})$ of autoantibodies in diabetic $(\mathrm{n}=12)$ or non-diabetic patients without depression $(\mathrm{n}=7)$. Ten micromolar concentrations of Y27632, a selective Rho-Associated Protein Kinase (ROCK) inhibitor, significantly prevented $(P<0.0001)$ neural progenitor cell process retraction induced by diabetes depression autoantibodies $(\mathrm{n}=5)$. Mice treated with diabetic depression autoantibodies $(\mathrm{n}=16$ from two different patients' autoantibodies) exhibited significantly reduced $(P=0.027)$ sucrose preference (anhedonia) compared to mice treated with diabetic control autoantibodies ( $\mathrm{n}=16$ from two different patients' autoantibodies).

Conclusion: These data suggest that autoantibodies in a subset of older adult diabetic depression inhibit endothelial cell survival, and impair process extension and survival in adult dentate gyrus neural progenitor cells in vitro.

Keywords: Autoantibodies; Diabetes Mellitus; Depression; Neural Progenitor Cells; Neurite Outgrowth

\section{Introduction}

Depression affects neurons in the prefrontal cortex and hippocampus [1] and depression increases among the millions of older adults affected by diabetes worldwide [2-4]. Although diabetes and depression share certain risk factors, e.g. physical inactivity, obesity, inflammation, and hypothalamic-pituitaryadrenal (HPA) axis dysregulation [5], the underlying mechanisms accounting for the substantially increased prevalence of comorbid depression in diabetes remain poorly understood [6]. One possibility is the well- known association between diabetic depression and microvascular complications [3], including diabetic micro-albuminuria [7]. Diabetic micro-albuminuria is a marker of incipient renal injury and diffuse capillary dysfunction [8]. Therefore unknown factors elaborated by injured glomerular capillary endothelial cells might play a causative role in subsets of diabetic depression.

Fibroblast Growth Factor 2 (FGF2) is a broad spectrum angiogenic and neurotrophic growth factor [9] which does not normally circulate, but is sequestered in extracellular tissue matrices through binding to its low affinity, Heparan Sulfate Proteoglycan (HSPG) co-receptor [10]. Fibroblast growth factor 2 increases in plasma in micro- or albuminuric diabetes [11] yet low plasma FGF2 levels occurred together with endothelial cell inhibitory autoantibodies in subsets of diabetic macular edema, and /or nephropathy $[12,13]$. Glomerular loss of HSPG occurs early in diabetic albuminuria [14] and since HSPG is a known target for autoimmunity [15], diabetic plasma autoantibodies which target the HSPG, FGF low affinity receptor may disrupt a broad spectrum of FGF2-mediated cellular effects [9] in neurons and endothelial cells.

The Dentate Gyrus (DG) region in the hippocampus is unique in that it is one of a few brain regions which contain adult neural stem cells [16]. FGF-2 is widely distributed throughout the rat brain [17], yet it co-localized together with HSPG in only a few 
regions, including the neurogenic region of the dentate gyrus [18]. Adult neurogenesis in the dentate gyrus has been implicated as an important target for the modulatory effects of stress, exercise, anti-depressant medications or electroconvulsant seizures in human depression or animal models of depressive-like behaviors [19-21]. Major depressive disorder was associated with markedly reduced endogenous FGF expression in mood-regulatory, frontocortical brain regions [22]. In the present study we tested a hypothesis that diabetic plasma IgG autoantibodies increase in subsets of middle-aged or older adult type 2 diabetes suffering with depression, and interfere with the (in vitro) differentiation of adult dentate gyrus neural progenitor cells required for their maturation into adult newborn DG neurons.

We examined plasma autoantibodies in 20 older adults with type 2 diabetic depression, and 30 age-matched (20 diabetic and 10 non-diabetic) non-depressed patients for effects on endothelial cell proliferation, neurite outgrowth in rat pheochromocytoma (PC12) cells, or process extension and survival in adult rat dentate gyrus neural progenitor cells.

\section{Subjects and Methods}

Informed consent was obtained from all study patients prior to any study procedure. Five of 89 participants enrolled in the Veterans Affairs Diabetes Trial (VADT) at the VA New Jersey had a diagnosis of depression and were included in the study. A control group of 10 VADT participants without depression having closest matching baseline characteristics (to diabetic depression subgroup) were chosen from among remaining patients for whom baseline VADT plasma was available for analysis. All VADT participants were screened with fasting C-peptide levels and did not have low C-peptide levels. Thirty-three additional diabetic or non-diabetic depression or control patients all evaluated in an IRB-approved VANJ study were selected for further analysis of the association between plasma autoantibodies and diabetic depression. Nearly all of the additional diabetic patients had fasting C-peptide levels which were not low.

\section{Diagnostic methods and subgroups}

Depression: All depressed patients were evaluated by psychiatry staff at the Veterans Affairs New Jersey Healthcare System. The diagnosis of depression, e.g. (major, recurrent vs. single episode, not otherwise specified, depressive disorder), was based on the Diagnostic and Statistical Manual IV criteria in use during the time period from November 2000 and November 2003 when nearly all patients were diagnosed. Patients were excluded if they had another psychiatric disorder associated with depression, e.g. PTSD ( $n=3)$, bipolar disorder $(n=2)$, or had an anxiety or mood disorder alone without depression. Participants with another neurodegenerative or a neoplastic disorder previously associated with neurite-inhibitory autoantibodies, but lacking depression, e.g. dementia, glaucoma, or newly diagnosed, untreated cancer were excluded from the analysis. Nineteen of the twenty diabetic depressed patients were treated with at least one anti-depressant medication for a minimum of six month's duration. An exception was an older diabetic depressed VADT participant who consistently refused medication treatment. Response to anti-depressant medication is defined here as significant improvement in dysthymic mood and overall functioning following 6-12 months' of continuous treatment (including dose-titration) with a single antidepressant medication, and was observed in only 6 of 16 patients. Treatment monitoring visits with a VA psychiatrist occurred in active depression patients over a range in durations lasting from seven months to six years. Data on response to anti-depressant medication was missing in three of twenty diabetic depression patients who initiated anti-depressant medication, but refused follow up visits in psychiatry clinic. None of the depressed patients in this study required electroconvulsive therapy. Painful diabetic neuropathy is defined according to previously reported criteria. Diabetic nephropathy is defined as urinary albumin excretion $\geq 300 \mathrm{mg} / \mathrm{g}$ creatinine or urinary protein excretion $\geq$ $500 \mathrm{mg} / \mathrm{g}$ creatinine. Age-related macular degeneration (AMD) has been reported to be associated with substantially increased occurrence of co-morbid depression [23]. Five of twenty diabetic depression and two of twenty diabetic, non-depressed participants suffered with AMD. Visual impairment secondary to AMD was moderate-severe in three of twenty diabetic depressed and one of twenty diabetic, non-depressed patients. Retinopathy is defined here as the presence of AMD, proliferative retinopathy or macular edema requiring laser photocoagulation.

Blood drawing: Baseline plasma samples were obtained from study participants prior to the initiation of study treatment in the VADT. Plasma samples obtained at the year 3 study visit were reassessed for endothelial cell autoantibody activity in all five VADT patients having depression. Plasma FGF-2 level was determined with a sensitive, specific two-site IRMA as previously described [24].

Protein-A affinity chromatography: Protein A chromatography was carried out as previously described [25]. The protein A eluate fractions consisted of total IgG isolated from plasma upon low $\mathrm{pH}$ elution from the protein A column. The 'active protein A eluate' is defined as the protein A eluate which caused significant inhibitory activity in endothelial cell survival assays.

Endothelial cell survival assay: Bovine pulmonary artery endothelial cells (Clonetics, Inc. San Diego, CA) were grown in Medium 199 plus 10\% fetal calf serum and endothelial cell growth medium (EGM, Clonetics, Inc., San Diego, CA). Endothelial cell number assays were carried out as previously reported [25]. Confluent cells were trypsinized and plated at 1 to $10 \times 10^{3}$ cells/ well in Medium 199 plus 10\% fetal calf serum in 96-well plates. After 1 or 2 days incubation for cells to reach 60 to $80 \%$ confluency, test fractions ( $30 \mu \mathrm{g} / \mathrm{mL}$ of protein A eluates of plasma) were added to wells in quadruplicate. After 48 hours' incubation in the presence of test fractions, cells were washed with PBS and processed for the colorimetric estimation of cell number, i.e. cellassociated acid phosphatase activity, as previously described [25]. There was a linear relationship between endothelial cell number and optical density at $410 \mathrm{~nm}$ as previously described [25]. Growth-promoting activity is expressed as a percentage of the control cell number for cells grown in the absence of test 
protein-A eluate fractions.

Neurite outgrowth inhibition assays: Undifferentiated rat pheochromocytoma PC12 cells obtained from ATCC (Manassa, VA) were grown in DMEM containing 10\% horse serum, $5 \%$ fetal calf serum and $10 \mathrm{ng} / \mathrm{mL} \mathrm{bFGF}$ was added in order to induce neuronal differentiation. Test protein-A eluate fractions (1:50 dilution $=30 \mu \mathrm{g} / \mathrm{mL}$ protein) were added to cells in duplicate or triplicate and incubated at $37^{\circ} \mathrm{C}$ for $48 \mathrm{hrs}$. Next the proportion of cells expressing a neurite of $>2$ cell diameters in length was counted and compared to the proportion of bFGF- stimulated neurite cell expression in dishes containing bFGF without added test fractions as previously described [13].

Adult neural progenitor cells: The stem cells were originally isolated from the dentate gyrus of adult Fisher 344 rats and were obtained from Dr. Fred Gage at the Salk Institute. The expanded cultures from single clones were infected with retrovirus to express GFP and selected as previously described [26]. The NPCs were plated at 15,000 cells $/ \mathrm{cm}^{2}$ on poly-L-ornithine and laminin in Dulbecco's Modified Eagle Medium (DMEM)/F12 medium high glucose (Omega Scientific, Tarzana, CA) containing N2 supplement (In vitrogen, Grand Island, NY), L-glutamine (2mM), penicillin/ streptomycin $(100 \mathrm{U} / \mathrm{ml})$ (Medium A) and FGF-2 $(20 \mathrm{ng} / \mathrm{ml}$, PeproTech, Rocky Hill, NJ). Upon reaching 70-90\% confluency, NPCs were trypsinized with $0.05 \%$ trypsin EDTA and plated at 144,500 cells $/ 35 \mathrm{~mm}$ dish in medium A without FGF-2. Cultures of GFP+ stem cells between passages 15 and 20 were used in this study. Test protein-A eluate fractions (5-7 $\mu \mathrm{g} / \mathrm{mL}$ protein) were added to cells on DIV 3 in duplicate or triplicate and incubated at $37^{\circ} \mathrm{C}$ for 4-6 days. On DIV 7, the proportion of cells expressing a neurite of $>2$ cell diameters in length was counted and compared to the proportion of cells expressing processes in dishes without added test fractions. NPC cell survival was assessed on DIV 9 as the proportion in two groups of 50-150 cells/dish that excluded $0.04 \%$ trypan blue.

\section{Behavioral experiments}

Surgery: All study procedures were approved by and carried out in accordance with the local Institutional Animal Care and Use Committee. Adult ( $\sim 12$ week) c57bl/6 male mice $(\sim 30 \mathrm{~g})$ were anesthetized with $5 \%$ isoflurane. For acute treatment, antibodies were delivered via intracerebroventicular (ICV) injection stereotaxically through a 30 gauge needle attached to a Hamilton syringe. Coordinates were: anteroposterior, $-0.1 \mathrm{~mm}$ with respect to bregma; lateral, $+1.0 \mathrm{~mm}$; ventral, $-3.0 \mathrm{~mm}$ with respect to the surface of the skull [27]. Mice received infusions of $1 \mu \mathrm{l}$ of antibodies ( $4 \mu \mathrm{g} / \mathrm{mL}$ ) delivered manually over $1 \mathrm{~min}$. The needle was left in place for 1 min after delivery to allow for diffusion of the antibodies. Investigators were blinded to which groups of mice had received an infusion of diabetic depression or diabetic control autoantibodies.

Sucrose preference test: One week following antibody infusions, anhedonia was measured using the sucrose preference test in each mouse's home cage. Two different autoantibodies in each subgroup of diabetic depression or diabetic control patients were tested on a total of 16 mice. Prior to testing, each mouse was acclimated to a $1 \%$ sucrose solution for 24 hours, via two$50 \mathrm{~mL}$ tubes with sipper tops. Following the completion of the sucrose preference pretrial, two days of sucrose preference were measured. During this time, each mouse had access to a sipper tube containing water and another containing $1 \%$ sucrose water. After one day, the locations of the bottles were switched to account for potential side preferences. All bottles are massed before and after each day of testing. Sucrose preference is equal to the ratio of total sucrose solution consumed to overall total solution consumed.

Tail suspension test: One day following the completion of sucrose preference testing (ten days following antibody infusions) behavioral despair was measured using the tail suspension test. One autoantibody in each subgroup of diabetic depression or diabetic control patients was tested on a total of 10 mice. The open-end of a $25 \mathrm{~mL}$ pipette was firmly secured to a metal shelf raised one-half meters above the bench top using packing tape. A water bath was positioned below the area of testing as a safety precaution. The final centimeter of each mouse-tail was secured to the closed-end of the pipette using $\approx 2$ centimeters of masking tape. Trial duration was six-minutes long. All trials were videotaped and immobile behavior during the final four minutes was measured manually by viewing the recording at a later time.

\section{Chemicals}

Protein A agarose was obtained from Pierce Chemical Co., (Rockford, IL). All other chemicals and reagents were analytical grade. Heparin (2-0,6-0) sulfated or un-sulfated disaccharides were obtained from Sigma Chem Co., Inc. (St. Louis, MO.).

\section{Protein determinations}

Protein concentrations were determined by a bicinchoninic acid protein assay kit (Pierce Chemical Co., Rockford, IL).

\section{Statistics}

All data are the mean \pm SD (Table 1,2) or SEM (Figure 1-4)

Table 1: Baseline clinical characteristics in the study participants.

\begin{tabular}{|c|c|c|c|c|}
\hline \multirow[b]{2}{*}{ Risk Factor } & \multicolumn{2}{|c|}{ Diabetes } & \multirow[b]{2}{*}{$P$-Value ${ }^{*}$} & \multirow{2}{*}{$\begin{array}{l}\text { No Diabetes } \\
\text { No Depres- } \\
\text { sion } \\
(\mathrm{N}=10)\end{array}$} \\
\hline & $\begin{array}{l}\text { Depression } \\
(\mathrm{N}=20)\end{array}$ & $\begin{array}{l}\text { No Depression } \\
(\mathrm{N}=\mathbf{2 0})\end{array}$ & & \\
\hline Age (years) & $60.7 \pm 11.0$ & $68.4 \pm 10.9$ & 0.154 & $67.7 \pm 17.1^{* *}$ \\
\hline $\mathrm{HbA}_{1 \mathrm{c}}(\%)$ & $9.2 \pm 1.4$ & $8.6 \pm 1.6$ & 0.174 & NT \\
\hline DM dur (yrs) & $19.4 \pm 11.7$ & $13.4 \pm 11.1$ & 0.117 & \\
\hline BMI $\left(\mathrm{kg} / \mathrm{m}^{2}\right)$ & $33.1 \pm 6.1$ & $31.1 \pm 5.3$ & 0.306 & $29.0+4.3^{* *}$ \\
\hline $\begin{array}{l}\text { Insulin use } \\
(\%)\end{array}$ & 85 & 50 & $0.016^{\wedge}$ & \\
\hline
\end{tabular}

$\mathrm{HbA}_{1 \mathrm{c}}$ - Glycosylated Hemoglobin, DM- Diabetes Mellitus, duration), BMIBody Mass Index, NT- Not Tested. ${ }^{*}$ T-test, or ${ }^{\wedge} \chi 2$ test: comparing diabetic depression to diabetic, no depression subgroups; ${ }^{* *}$ T-test $P=0.38,{ }^{* *} P>$ 0.05 compared to diabetic depression subgroup. 
as indicated. Comparisons were made by Student's t-test for a continuous variable, or by Chi-square $\left(\chi^{2}\right)$ test for dichotomous variables with a significance level, $P=0.05$. For a multiple test, however, the $p$-value was adjusted by the Bonferonni correction method, dividing it by the number of comparisons.

\section{Results}

\section{Baseline characteristics in study participants}

Diabetic depression patients did not differ significantly from diabetic patients without depression in the baseline mean age, body mass index, glycosylated hemoglobin or duration of diabetes [Table 1]. A significantly higher proportion of patients in the diabetic depression subgroup $(P=0.016)$ were being treated with insulin at the baseline study examination [Table 1].

\section{Association between diabetic depression and baseline microvascular complications}

A significantly higher proportion of diabetic depression patients had baseline diabetic maculopathy $(P=0.0098)$ or baseline nephropathy $(P=0.018)$ compared to diabetes without depression [Table 2]. Diabetes depression vs. (no depression patient subgroups) did not differ significantly in the proportions with baseline inhibitory endothelial cell autoantibodies or low plasma FGF-2 concentration [Table 2].

Endothelial cell inhibitory activity in the protein A eluates of plasma: association with diabetic depression

Protein-A eluates $(30 \mu \mathrm{g} / \mathrm{mL})$ in diabetic depression patients caused significant $(P=0.014)$ inhibition of EC survival compared to the protein-A eluates in diabetes without depression [Figure 1]. The diabetic depression protein A eluates $(30 \mu \mathrm{g} / \mathrm{mL})$ also caused significant $(P=0.001)$ inhibition in EC survival compared to the protein A eluates from control, non-diabetic patients without depression [Figure 1].

Neurite outgrowth inhibition in protein A eluates of plasma: association with diabetic depression

Protein A eluates $(30 \mu \mathrm{g} / \mathrm{mL})$ in diabetic depression patients caused significant $(P<0.001)$ inhibition of FGF-2 induced, PC12 neurite outgrowth compared to similar concentrations of the protein A eluates from diabetic or non-diabetic participants

Table 2: Association between diabetic depression and co-morbid microvascular complications.

\begin{tabular}{|c|c|c|c|c|}
\hline Risk Factor & $\begin{array}{c}\text { Depression } \\
(\mathrm{N}=20)\end{array}$ & $\begin{array}{c}\text { Diabetes } \\
\text { No Depression } \\
(\mathrm{N}=20)\end{array}$ & $P$-Value ${ }^{*}$ & $\begin{array}{l}\text { No Diabetes } \\
\text { No Depression } \\
(\mathrm{N}=10)\end{array}$ \\
\hline ME, AMD (\%) & 80 & 40 & 0.0098 & NT \\
\hline Nephropathy (\%) & 50 & 15 & 0.018 & NT \\
\hline Painful neur (\%) & 70 & 40 & 0.057 & NT \\
\hline Inhib EC act (\%) & 75 & 65 & 0.490 & $0^{* *}$ \\
\hline Low FGF-2 (\%)^ & 88 & 65 & 0.101 & $86(7)$ \\
\hline
\end{tabular}

${ }^{*} \chi 2$ test comparing diabetic depression to diabetic no depression subgroups. Neur-(opathy), ME- Macular Edema, AMD- Age- Related Macular Degeneration, NT- Not Tested. ( ) number tested. Inhib-(itory) EC endothelial cell activity represents proportions of study participants having protein A eluate fraction which caused EC survival $\leq 90 \%$, as described in Methods. ${ }^{* *} \chi 2$ test, $P=0.00011$ compared to diabetic depression subgroup. ${ }^{\wedge}$ Low plasma FGF-2 is defined as $\leq 4.0 \mathrm{pg} / \mathrm{mL}$

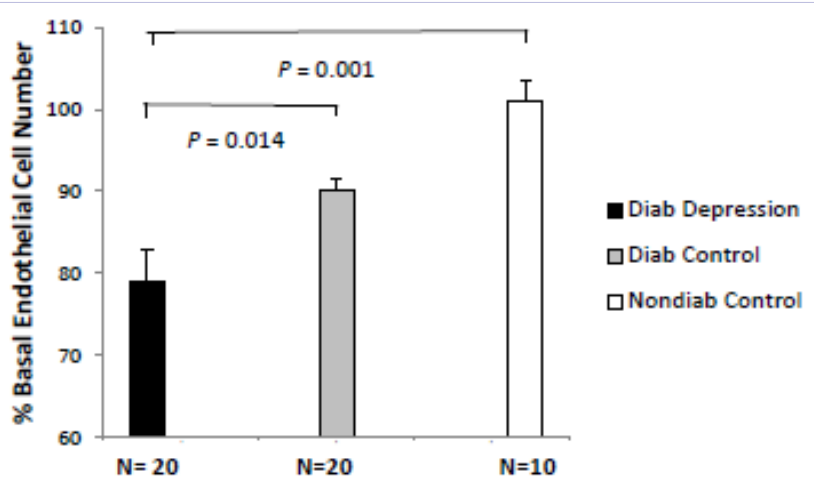

Figure 1: Effect of diabetic depression (or control group autoantibodies) on survival in bovine pulmonary artery endothelial cells. Protein-A eluate $(30 \mu \mathrm{g} / \mathrm{mL})$ was incubated with bovine pulmonary artery endothelial cells for two days as described in Methods. Results (mean + SEM) are percent of basal endothelial cell number. 
A

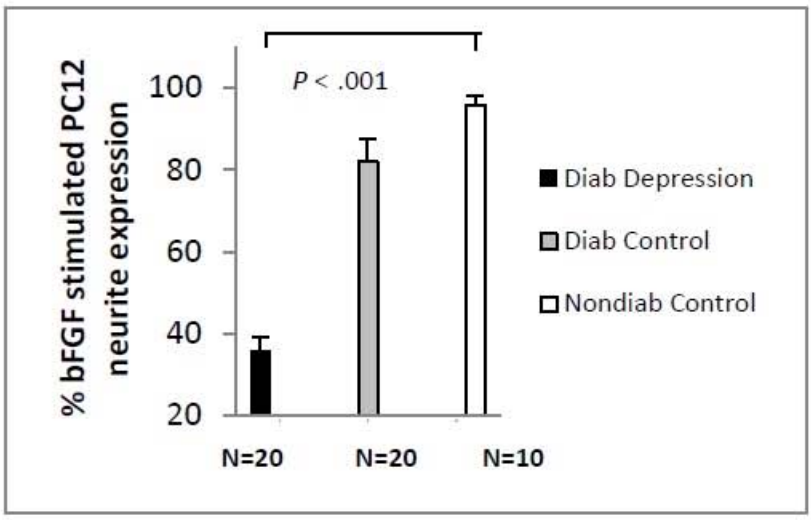

$\mathrm{C}$

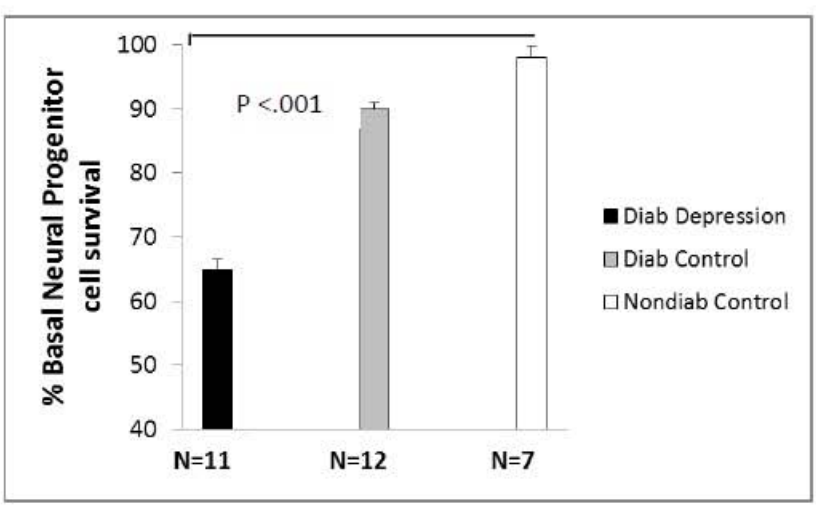

E

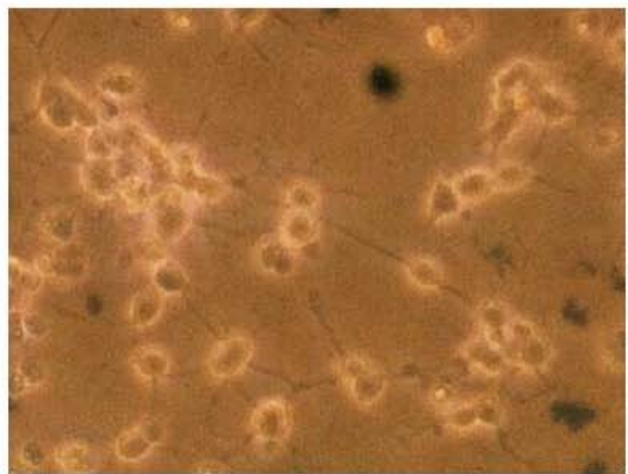

$\mathrm{B}$

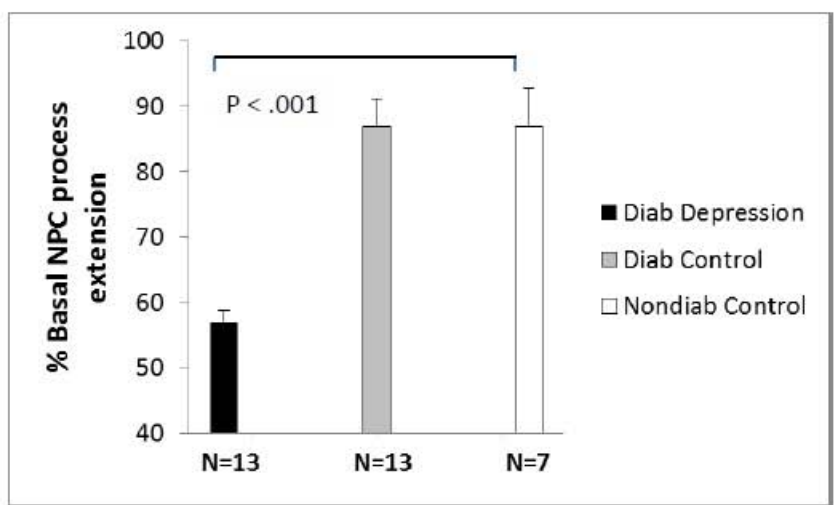

$\mathrm{D}$

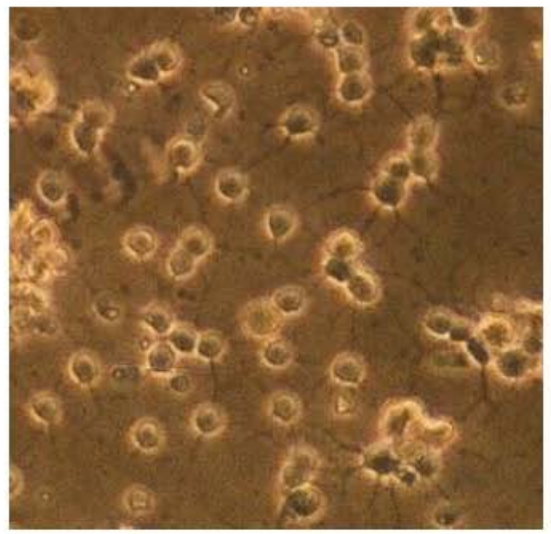

F

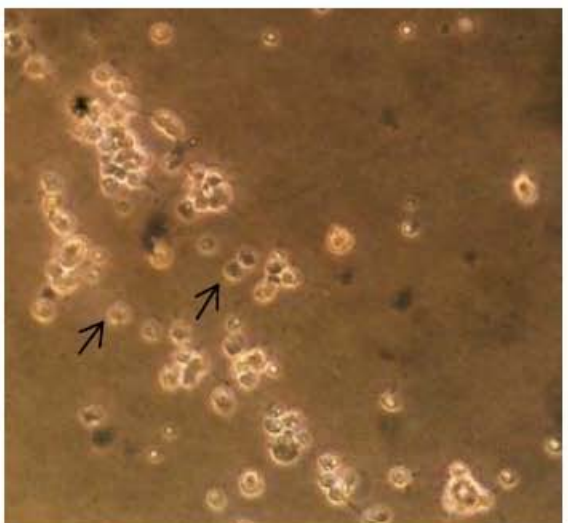

Figure 2: Effect of diabetic depression (or control group autoantibodies) on neurite extension in A) rat pheochromocytoma (PC12) cells, or process extension B) or survival C) in adult rat dentate gyrus neural progenitor (NPC) cells. A) Protein-A eluate (30 $\mathrm{gg} / \mathrm{mL})$ was incubated with PC12 cells and bFGF (A), or lower concentration (5-7 $\mu \mathrm{g} / \mathrm{mL}) \mathrm{B}, \mathrm{C}$ ) was incubated with NPCs without bFGF as described in Methods. Results (mean + SEM) are percent of neurite or process extension $(\mathrm{A}, \mathrm{B})$; or percent of basal NPC cell number C)compared to no added protein-A eluate. D-F) Morphology in DIV7 adult dentate gyrus neural progenitor cells after 4 days' exposure to $5-7 \mu \mathrm{g} / \mathrm{mL}$ concentrations of protein A eluate from D) no added protein-A eluate fraction E) representative diabetic patient without depression, or F)diabetic depression patient. Unstained cell images, x100 magnification, were obtained using a Nikon TMS, x10 lens (0.25), phase contrast microscope. Arrows F) indicate smaller cell bodies in neurons exposed to diabetic depression autoantibodies.

Citation: Zimering MB, Behnke JA, Thakker-Varia S, Alder J (2015) Autoantibodies in Human Diabetic Depression Inhibit Adult Neural Progenitor Cells In vitro and Induce Depressive-Like Behavior in Rodents. J Endocrinol Diab 2(2): 11. DOI: 
A

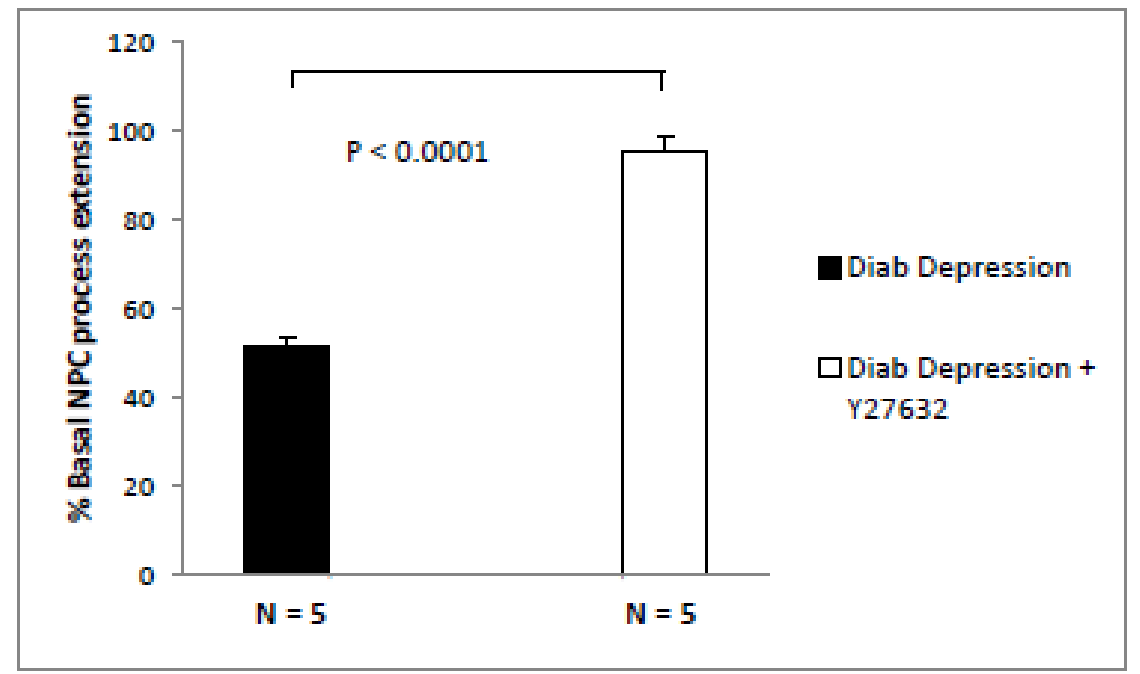

B

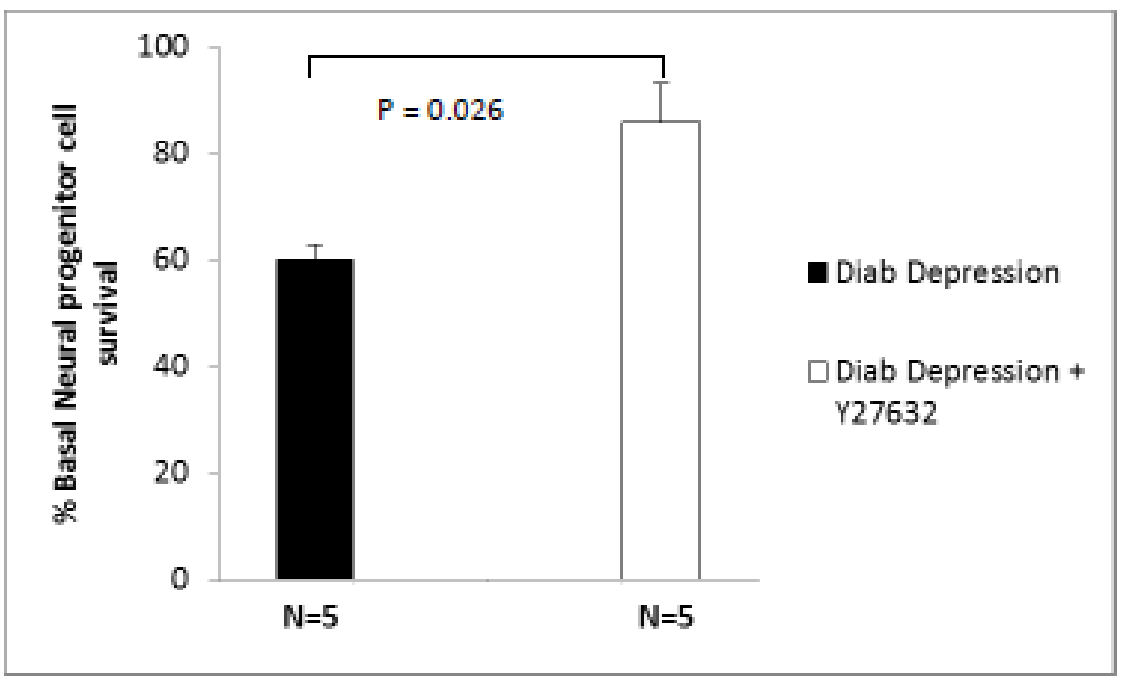

Figure 3: Rho kinase (ROCK) inhibitor antagonizes neurite-inhibitory or survival-reducing effects of diabetic depression autoantibodies in dentate gyrus neural progenitor cells A-B) Diabetic depression protein A eluate $(5-7 \mu \mathrm{g} / \mathrm{mL})$ from five different patients was incubated with adult rat dentate gyrus neural progenitor cells (NPC) in the presence (open bars) or absence (solid bars) of $10 \mu \mathrm{M}$ concentrations of Y27632, a selective Rho kinase inhibitor. Results (mean + SEM) are percent of process extension (A); or percent of basal NPC cell number (B) compared to no added protein-A eluate.

without depression [Figure 2a].

\section{Diabetic depression protein A eluates inhibit dentate gyrus neurogenesis}

Neural Progenitor Cells [NPC] develop in close apposition to capillaries in the dentate gyrus of the hippocampus [28]. Fibroblast growth factor 2 is an autocrine endothelial cell growth factor [9] important for maintaining neural stem cell survival, and proliferation [28] in vitro. The diabetic depression protein A eluates $(5-7 \mu \mathrm{g} / \mathrm{mL}$ protein) caused significant $(P<0.001)$ inhibition of mean NPC process extension [Figure $2 \mathrm{~b}$ ] and significant $(P<0.001)$ reduction in mean NPC survival compared to protein A eluates from diabetic or non-diabetic patients without depression [Figure 2c].

Diabetic depression autoantibodies $(5-7 \mu \mathrm{g} / \mathrm{mL}$ protein) substantially inhibited NPC branching process extension, and also caused substantial contraction in NPC cells [arrows, Figure 2f] compared to the morphology in NPC cells cultured without autoantibodies [Figure $2 \mathrm{~d}$ or incubated with similar concentrations of protein A eluates from diabetes without depression [Figure 2e]. 
A

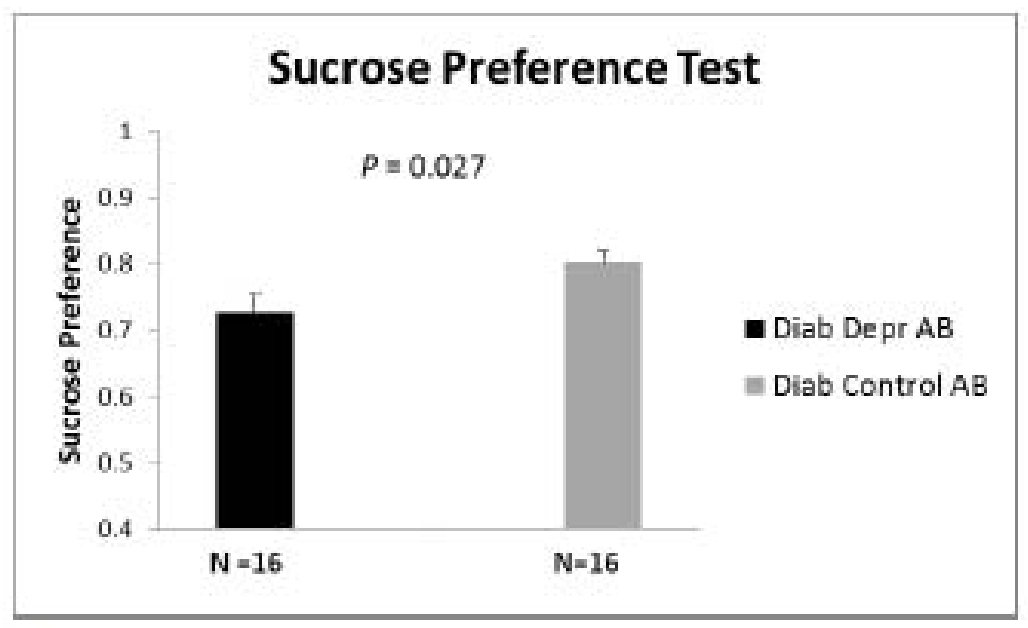

B

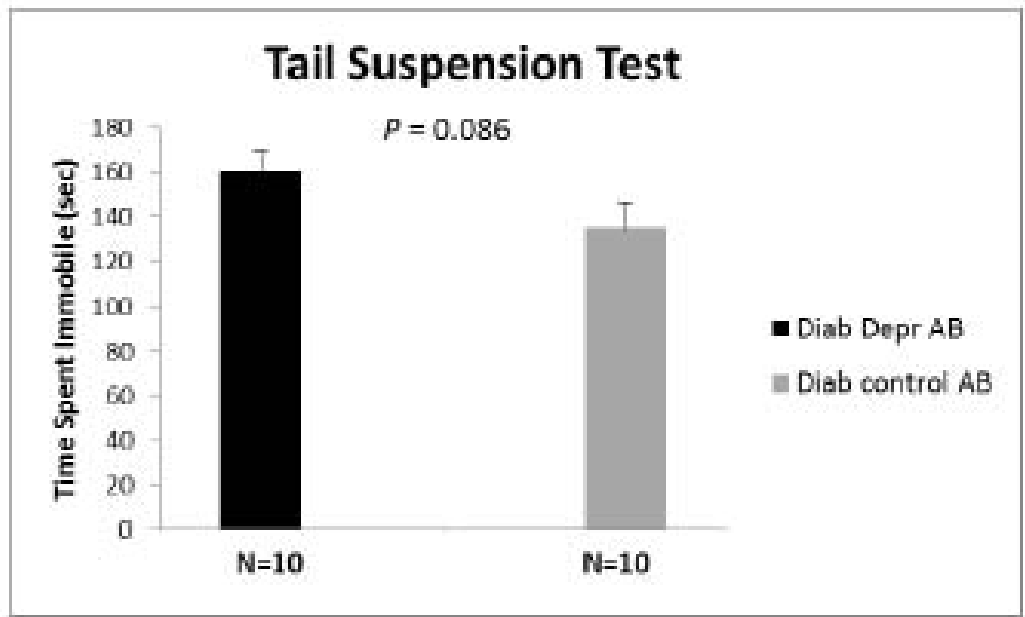

Figure 4: Effect of intracerebroventricular injection of diabetic depression or diabetic control autoantibodies on depression-like behavior in mice A) anhedonia (sucrose preference) or B) despair (tail suspension immobility). Four $\mu \mathrm{g} / \mathrm{mL}$ concentrations of the protein-A eluate fraction from two diabetic depression patients or two age-matched diabetic patients without depression A) was injected via the intracerebroventricular route into mice (total $\mathrm{n}=16$ mice in each test group) in each of two separate experiments. Sucrose preference (mean + SEM) was determined 7 days later as described in Methods and represents pooled results from the two separate experiments. In the latter of the two experiments, B) immobility in tail suspension test (mean + SEM) was determined 10 days after ICV injection of protein A eluates $(4 \mu \mathrm{g} / \mathrm{mL})$ from one diabetic depression and one age-matched control diabetic patient ( $\mathrm{n}=10$ mice in each test group), as described in Methods.

\section{Rho kinase inhibitor interferes with inhibitory effects of diabetic depression autoantibodies on NPC neurite outgrowth and cell survival}

Mean process extension in NPC cells co-incubated with diabetic depression autoantibodies $(5-7 \mu \mathrm{g} / \mathrm{mL})(\mathrm{n}=5)$ and Y27632 $(10 \mu \mathrm{M})$ significantly $(P<0.0001)$ exceeded levels in NPC incubated with diabetic depression autoantibodies alone $(n=5)$ [Figure 3a]. Mean survival in NPC cells co-incubated with diabetic depression autoantibodies and Y27632 $(10 \mu \mathrm{M})$ was also significantly $(P=0.026)$ higher than the levels in NPC cells incubated with diabetic depression autoantibodies alone $(\mathrm{n}=5)$ [Figure 3b]. Y27632 alone $(10 \mu \mathrm{M})$ caused a modest, non- significant $(P=0.077)$ increase in mean NPC process extension compared to levels in control, untreated NPC cells (data not shown).

\section{Effect of proteoglycan or heparin GAG sulfation on NPC morphology}

Heparin or heparan proteoglycan sulfation mediates high affinity FGF-2 binding, which for the low affinity HSPG receptor, is required for FGF-2- mediated endothelial cell activation or PC12 cell neurite expression [9]. In a prior study, sodium chlorate (30 mM), an inhibitor of proteoglycan sulfation [29], abrogated diabetic painful neuropathy autoantibody-induced PC12 neurite 
retraction [13].

We next tested for involvement of sulfated proteoglycans or heparin GAG in the maintenance of a differentiated, neuriticallyextended phenotype in NPC cells cultured without FGF-2. Sodium chlorate (5 mM) caused NPC dendrites to rapidly detach from the matrix and degenerate. At higher sodium chlorate concentrations (10-30 mM), NPC cell bodies also rapidly contracted, detached from the matrix and died. Ten microgram/mL concentrations of a specific (6-0,2-0) densely sulfated, heparin disaccharide caused NPC neurites to retract, and shrink by up to $50 \%$ after five minutes. After an additional five minutes' exposure, highly branched NPC cells neurites had acquired a 'dystrophic' morphology without effects on NPC cell body morphology. On the other hand, five-ten minutes' exposure to (6-0,2-0) de-sulfated heparin disaccharide $(10 \mu \mathrm{g} / \mathrm{mL})$ caused NPC neurite- lengthening without any discernable effect on NPC cell body morphology (data not shown). The simultaneous addition of $10 \mu \mathrm{g} / \mathrm{mL}$ concentrations of $(6-0,2-$ 0 ) densely sulfated, heparin disaccharide together with $(5 \mu \mathrm{g} / \mathrm{mL})$ diabetic depression autoantibodies caused neurite retraction, dendritic simplification and distal neurite degeneration (after 10 minutes exposure), the latter was characterized by vacuolization, beading and distal neuritic detachment from the matrix. Diabetic depression autoantibodies $(5 \mu \mathrm{g} / \mathrm{mL})$ alone caused NPC cell contraction and modest (15-25\%) neurite retraction within 10 minutes of addition to the cells.

\section{Intracerebroventricular injection of diabetic depression vs control autoantibodies: effect on depression behavior in mice}

ICV injection of low concentrations of diabetic depression autoantibodies $(4 \mu \mathrm{g} / \mathrm{mL}$ ) from two different patients caused a significant decrease $(P=0.027)$ in sucrose preference compared to mice that received nearly identical concentrations (ICV route) of autoantibodies from two diabetic control, (i.e. non-depressed) patients [Figure 4a]. There was a nearly significant association $(P=0.086)$ between increased immobility in the tail suspension test in mice (evaluated ten days after) ICV injection of diabetes depression vs. diabetes no depression autoantibodies [Figure 4b].

\section{Increased endothelial cell inhibitory potency in diabetic depression protein A eluates}

Half-maximal EC inhibitory concentrations (4-7 $\mu \mathrm{g} / \mathrm{mL})$ [33] of the protein A eluates from low FGF-2, diabetic depression plasma $(n=5)$ caused significantly $(P=0.014)$ greater mean inhibition of EC survival $(79 \pm 6 \%)$ compared to the protein A eluates from low FGF-2, diabetes without depression plasma $(n=4)(92 \pm 2 \%)$ (data not shown).

\section{Physiochemical characterization of diabetic depression protein A eluates}

Mass spectrometry of diabetic depression protein A eluates $(\mathrm{n}=2)$ revealed MW peaks (56 kD), (112kD), (150kD), (75kD), (23kD) corresponding to IgG heavy chains, intact IgG, or IgG light chains, respectively, as previously reported in subsets of diabetic retinopathic, protein A eluates [13]. Endothelial cell inhibitory activity in diabetic depression protein A eluates $(n=2)$ was inhibited: $50 \%$ by treatment with reducing agents, $(6 \mathrm{mM}$ dithiothreitol for 2 hours at room temperature), or $43-75 \%$ by strong heat $\left(95^{\circ} \mathrm{C}\right.$ for 5 minutes), as previously reported [30].

\section{Discussion}

The present data demonstrate that plasma autoantibodies in older adult type 2 diabetes with 'difficult-to-treat' depression significantly inhibit adult dentate gyrus neural progenitor cell process extension and survival. To our knowledge, this is the first evidence that circulating diabetic depression autoantibodies can impair the differentiation and survival of maturing adult dentate gyrus neural progenitor cells, a population of cells which are important in the therapeutic response to anti-depressant medications.

The association reported here between highly potent anti-EC autoantibodies and co-morbid depression is striking and novel. Adult dentate gyrus neural progenitor cells develop in a vascular microenvironment enriched in angiogenic growth factors [31] suggesting they may be a target for circulating anti-endothelial, anti-neuronal autoantibodies. Our finding that maculopathy and nephropathy were increased in diabetic depression agrees with previous reports [3]. Since potent diabetic anti-EC autoantibodies were previously demonstrated to activate Rho A/Rho kinase signaling in EC [30], and Rho A/Rho kinase activation is associated with endothelial cell barrier dysfunction [32], diabetic plasma autoantibodies which can target endothelial or endothelial-like, vascular cells (i.e. adult neural stem cells) [31] may not only have a causative role in mediating increased capillary permeability underlying diabetic macular edema and/or nephropathy, but also in subsets of co-morbid depression occurring together with these microvascular complications.

Prior findings and the current data strongly suggest that subsets of diabetic depression autoantibodies target cell surface HSPG abundant on neurons and endothelial cells. First, the diabetic maculopathy/nephropathy autoantibodies bound with specific, high affinity to heparin Sepharose columns [24]. Second, they displayed increased binding to PC-12 cell-derived purified HSPG [13]. Third, the proteoglycan sulfation inhibitor, chlorate, abrogated autoantibody-induced PC12 neurite retraction [33]. Fourth, the autoantibodies caused endothelial cell contraction, loss of cell attachment and apoptosis by a mechanism involving activation of RhoA/Rho kinase, increased intracellular $\mathrm{Ca}^{2+}$ release, and caspase activation [30]. Taken together with the present finding that diabetic depression autoantibodies caused contraction and decreased NPC survival (effects which were mimicked by chlorate ion), diabetic depression autoantibodies may target sulfated proteoglycans on the NPC cell surface involved in mediating attachment to heparin-binding substances in the underlying matrix.

NPC neuritic retraction $v s$ outgrowth was differentially modulated by densely- sulfated or unsulfated forms of a heparin disaccharide, respectively. These findings may be consistent with the reported effects (on neurite outgrowth) of substances which inhibit or enhance the interaction between (NPC) 
cell surface HSPG and matrix-associated, heparin sulfate- or heparan sulfate- binding substances [34]. Antibodies which cross-linked cell surface HSPG were reported to induce Rhodependent cytoskeleton changes, e.g. in actin stress fibers, mediating fibroblast cell shape changes [35]. Since Rho A/Rho kinase signaling activation in neurons also mediates dendritic simplification and neuritic retraction [36], our finding that a selective Rho kinase inhibitor interfered with neurite retraction and NPC cell killing by diabetic depression autoantibodies suggests possible involvement of ROCK activation in the mechanism of autoantibody-mediated effects in NPCs.

The precise identity and tissue origin(s) of the auto-antigens targeted by diabetic depression autoantibodies is unknown TNF- $\alpha$ induced endothelial cells to express a specific ( $\mathrm{N}$-sulfated, 2-0, 6-0 sulfated) $)_{3}$ heparan sulfate domain important for mediating FGF-2 and FGFR binding [37]. Of interest, phage display-derived antibodies specific for the same, densely sulfated heparan GAG domain induced apoptosis in lung epithelial cells [37] consistent with the possibility that tissue fate specification is mediated in part by HSPG heparan sulfate microstructural variation. The fine specificity in HSPG GAG saccharide structures is thought to play an important role in neuronal development by modulating interactions between cell surface receptors and heparin binding growth factors whose spatio-temporal expression is tightly developmentally-regulated [34]. More study is needed to determine whether autoantibodies arising under pro-inflammatory conditions such as poorly-controlled diabetes which target HSPGs elaborated from peripheral tissues, e.g. glomerular capillary, cross-react with HSPGs expressed in certain neuronal cells.

Even though adult, obese type 2 diabetes is not a systemic autoimmune disease, the prevalence of anti-EC autoantibodies $(30 \%)$ in a VADT, obese type 2 DM cohort comprised of 182 older adults [12] was similar to that which was previously reported in adult type 1 diabetes [38]. More potent anti-EC autoantibodies were found in a higher percentage (38\%) or $117 / 305$ proteinuric, adult type 2 diabetic nephropathy from the VA-NEPHRON D trial [39]. Baseline insulin or fibrate medication use were risk factors significantly inversely associated with the baseline presence of anti-EC autoantibodies in the VADT cohort [12] consistent with a possible role for up- or down-regulation of EC heparanase secretion (in vitro) by pro-inflammatory cytokines [40] or by insulin [41], respectively in the elaboration of EC-derived HSPG.

Adult rat or mouse NPCs both express HSPG required for FGF2 mediated proliferation [42] with substantially higher HPSG expression occurring in adult rat NPCs [42]. Whether decreased neurogenesis plays a role in the induction of depressive-like behavior, or might be preventable through administration of a selective ROCK inhibitor are unknown and require further study. The current data might be consistent with prior reports indicating that Rho A activation in adult hippocampal neural progenitor cells suppressed neurogenesis [43]. It is not known, however, whether suppression of neurogenesis by ROCK-activating autoantibodies might account in part for the observation that many of the diabetic depression patients in the current study cohort were poorly- responsive to treatment with SSRI anti-depressant medications.

A limitation of our study is that the results may only apply to older men with longstanding type 2 diabetes who had a substantial burden of microvascular diabetic complications. More study is needed in other populations including women with diabetes. Anti-endothelial, anti-neuronal autoantibodies may result from tissue injury and have only a limited bystander role in depression. Yet our preliminary results indicate persistence of depressive symptoms in $4 / 4$ diabetic patients in whom plasma autoantibody persisted for three years or longer. On the other hand, spontaneous disappearance of autoantibodies was associated with excellent treatment response to a selective serotonin reuptake inhibitor medication in a 72 year- old man with major depression.

Depression occurring in older adults remains underrecognized and undertreated [44]. A much larger randomized study would be required to test whether NPC-targeting autoantibodies might be useful as a biomarker for the early detection of depression subsets. Despite accumulating evidence linking alterations in the rate of adult dentate gyrus hippocampal neurogenesis with depression, the function of newborn adult DG neurons in hippocampus networks remains poorly understood [45]. Since immature adult dentate gyrus neurons were reported to be hyper-excitable compared to mature DG neurons [45] one possibility is that DG NPCs might have increased susceptibility to autoantibody-induced excitotoxicity, as was reported previously in rat hippocampal neurons exposed to low concentrations of cancer fatigue/depression autoantibodies [13].

\section{Conclusion}

In conclusion, the current data suggest a novel mechanism by which anti-endothelial cell, anti-neural progenitor cell autoantibodies may contribute to pathophysiology in subsets of depression experienced by older adult men with type 2 diabetes having an increased burden of microvascular complications including diabetic nephropathy.

\section{Acknowledgements}

We thank Dr. Carlos Abraira, and Dr. William Duckworth, VADT Co-Chairmen for their support and Dr. Gideon Bahn for helpful suggestions. This study was supported in part by a grant (to MBZ) from the Veterans Biomedical Research Institute, East Orange, NJ; and by the Department of Veterans Affairs Cooperative Studies Program, Office of Research and Development, Washington, DC.

The authors report no conflict of interest that would affect the objectivity of the findings presented.

\section{References}

1. Banasr M, Dwyer JM, Duman RS. Cell atrophy and loss in depression: reversal by antidepressant treatment. Curr Opin Cell Biol. 2011; 23(6):730-737. doi: 10.1016/j.ceb.2011.09.002.

2. Aziz R, Steffens DC. What are the causes of late-life depression? Psychiatr Clin North Am. 2013; 36(4):497-516. doi: 10.1016/j. psc.2013.08.001. 
3. Sullivan MD, O'Connor P, Feeney P, Hire D, Simmons DL, Raisch DW, et al. Depression predicts all-cause mortality: epidemiological evaluation from the ACCORD HRQL substudy. Diabetes Care. 2012; 35(8):170815. doi: $10.2337 /$ dc11-1791.

4. Lin EH, Rutter CM, Katon W, Heckbert SR, Ciechanowski P, Oliver MM, et al. Depression and advanced complications of diabetes: a prospective cohort study. Diabetes Care. 2010; 33(2):264-9. doi: 10.2337/dc09-1068.

5. Holt RIG, de Groot M, Lucki I, Hunter CM, Sartorius N, Golden SH NIDDK International Conference Report on Diabetes and Depression: Current Understanding and Future Directions. Diabetes Care. 2014; 37(8):2067-2077. doi: 10.2337/dc13-2134.

6. Anderson RJ, Freedland KE, Clouse RE, Lustman PJ The prevalence of comorbid depression in adults with diabetes: a meta-analysis Diabetes Care 2001; 24(6):1069-1078.

7. Yu MK, Katon W, Young BA. Diabetes self-care, major depression, and chronic kidney disease in an outpatient diabetic population. Nephron Clin Pract. 2013; 124(1-2):106-112. doi: 10.1159/000355551.

8. Deckert T, Feldt-Rasmussen B, Borch-Johnsen K, Jensen T, KofoedEnevoldsen A. Albuminuria reflects widespread vascular damage. The Steno hypothesis. Diabetologia. 1989; 32(4):219-226.

9. Gospodarowicz D, Ferrara N, Schweigerer L, Neufeld G. Structural characterization and biological functions of fibroblast growth factor. Endocr Rev. 1987; 8(2):95-114.

10. Vlodavsky I, Fuks Z, Ishai-Michaeli R, Bashkin P, Levi E, Korner G, et al. Extracellular matrix-resident basic fibroblast growth factor: implication for the control of angiogenesis. J Cell Biochem. 1991; 45(2):167-176

11.Zimering MB, Eng J. Increased basic fibroblast growth factor-like substance in plasma from a subset of middle-aged or elderly male diabetic patients with microalbuminuria or proteinuria. J Clin Endocrinol Metab. 1996; 81(12):4446-4452.

12.Zimering MB, Anderson RJ, Moritz TE, Ge L; Investigators for the VADT. Endothelial cell inhibitory autoantibodies are associated with laser photocoagulation in adults from the Veterans Affairs Diabetes Trial. Metabolism. 2009; 58(6):882-887. doi: 10.1016/j. metabol.2009.02.023.

13.Zimering MB, Alder J, Pan Z, Donnelly RJ. Anti-endothelial and antineuronal effects from auto-antibodies in subsets of adult diabetes having a cluster of microvascular complications. Diabetes Res Clin Pract. 2011; 93(1):95-105. doi: 10.1016/j.diabres.2011.03.029.

14. Wijnhoven TJ, van den Hoven MJ, Ding H, van Kuppevelt TH, van der Vlag J, Berden $\mathrm{JH}$, et al. Heparanase induces a differential loss of heparan sulphate domains in overt diabetic nephropathy. Diabetologia. 2008; 51(2):372-382.

15. Renaudineau Y, Révélen $R$, Dueymes $M$, Levy $Y$, Youinou $P$. Autoantibodies to heparan sulfate proteoglycans. Autoimmun Rev. 2002; 1(5):305-312.

16. Palmer TD, Takahashi J, Gage FH. The adult rat hippocampus contains primordial neural stem cells. Mol Cell Neurosci. 1997; 8(6):389-404.

17. Fuxe K, Tinner B, Zoli M, Pettersson RF, Baird A, Biagini G, et al Computer-assisted mapping of basic fibroblast growth factor immunoreactive nerve cell populations in the rat brain. J Chem Neuroanat. 1996; 11(1):13-35

18. Fuxe K, Chadi G, Tinner B, Agnati LF, Pettersson R, David G. On the regional distribution of heparan sulfate proteoglycan immunoreactivity in the rat brain. Brain Res. 1994; 636(1):131-138

19. Warner-Schmidt JL, Duman RS. Hippocampal neurogenesis: opposing effects of stress and antidepressant treatment. Hippocampus. 2006; 16(3):239-249.

20. Newton SS, Collier EF, Hunsberger J, Adams D, Terwilliger R, Selvanayagam E, et al. Gene profile of electroconvulsive seizures: induction of neurotrophic and angiogenic factors. J Neurosci. 2003; 23(34):10841-10851

21. Fuchs E. Social stress in tree shrews as an animal model of depression: an example of a behavioral model of a CNS disorder. CNS Spectr. 2005; 10(3):182-190.

22. Evans SJ, Choudary PV, Neal CR, Li JZ, Vawter MP, Tomita H, et al. Dysregulation of the fibroblast growth factor system in major depression. Proc Natl Acad Sci USA. 2004; 101(43):15506-15511.

23. Brody BL, Gamst AC, Williams RA, Smith AR, Lau PW, Dolnak D, et al. Depression, visual acuity, comorbidity, and disability associated with age-related macular degeneration. Ophthalmology. 2001; 108(10):1893-1900.

24. Zimering MB, Anderson RJ, Moritz TE, Ge L; Investigators for the VADT. Low plasma basic fibroblast growth factor is associated with laser photocoagulation treatment in adult type 2 diabetes mellitus from the Veterans Affairs Diabetes Trial. Metabolism. 2009; 58(3):393-400. doi: 10.1016/j.metabol.2008.10.014.

25.Zimering MB, Thakker-Varia S. Increased fibroblast growth factorlike autoantibodies in serum from a subset of patients with cancerassociated hypercalcemia. Life Sci. 2002; 71(25):2939-2959.

26.Song HJ, Stevens CF, Gage FH. Neural stem cells from adult hippocampus develop essential properties of functional CNS neurons. Nat Neurosci. 2002; 5(5):438-445.

27. Bartolomucci A, Possenti R, Levi A, Pavone F, Moles A. The role of the vgf gene and VGF-derived peptides in nutrition and metabolism. Genes Nutr. 2007; 2(2):169-180. doi: 10.1007/s12263-007-0047-0.

28. Palmer TD, Ray J, Gage FH. FGF-2-responsive neuronal progenitors reside in proliferative and quiescent regions of the adult rodent brain. Mol Cell Neurosci. 1995; 6(5):474-486.

29. Keller KM, Brauer PR, Keller JM. Modulation of cell surface heparan sulfate structure by growth of cells in the presence of chlorate. Biochemistry. 1989; 28(20):8100-8107.

30.Zimering, M. B., and Pan, Z. Autoantibodies in type 2 diabetes induce stress fiber formation and apoptosis in endothelial cells. J Clin Endocrinol Metab. 2009; 94(6):2171-2177. doi: 10.1210/jc.20082354.

31.Palmer TD, Willhoite AR, Gage FH. Vascular niche for adult hippocampal neurogenesis. J Comp Neurol. 2000; 425(4):479-494.

32.van Nieuw Amerongen GP, Beckers CM, Achekar ID, Zeeman S, Musters RJ, van Hinsbergh VW. Involvement of Rho kinase in endothelial barrier maintenance. Arterioscler Thromb Vasc Biol 2007; 27(11):2332-2339.

33.Zimering MB, Moritz TE, Donnelly RJ. Anti-neurotrophic effects from autoantibodies in adult diabetes having primary open angle glaucoma or dementia. Front Endocrinol (Lausanne). 2013; 4:58. doi: 10.3389/ fendo.2013.00058.

34. Kinnunen A, Niemi M, Kinnunen T, Kaksonen M, Nolo R, Rauvala H. Heparan sulphate and HB-GAM (heparin-binding growth-associated molecule) in the development of the thalamocortical pathway of rat brain. Eur J Neurosci. 1999; 11(2):491-502. 
35. Saoncella S, Echtermeyer F, Denhez F, Nowlen JK, Mosher DF, Robinson SD, et al. Syndecan-4 signals cooperatively with integrins in a Rho-dependent manner in the assembly of focal adhesions and actin stress fibers. Proc Natl Acad Sci USA. 1999; 96(6):2805-2810.

36. Katoh H, Aoki J, Ichikawa A, Negishi M. p160 RhoA-binding kinase ROKalpha induces neurite retraction. J Biol Chem. 1998; 273(5):24892492.

37. Smits NC, Kurup S, Rops AL, ten Dam GB, Massuger LF, Hafmans T, et al. The heparan sulfate motif (GlcNS6S-IdoA2S)3, common in heparin, has a strict topography and is involved in cell behavior and disease. J Biol Chem. 2010; 285(52):41143-41151. doi: 10.1074/jbc. M110.153791.

38. Wangel AG, Kontiainen S, Scheinin T, Schlenzka A, Wangel D, Mäenpää J. Anti-endothelial cell antibodies in insulin-dependent diabetes mellitus. Clin Exp Immunol. 1992; 88(3):410-413.

39.Zimering MB, Zhang JH, Guarino PD, Emanuele N, McCullough PA Fried LF; Investigators for the VA NEPHRON-D. Endothelial cell autoantibodies in predicting declining renal function, end-stage renal disease, or death in adult type 2 diabetic nephropathy. Front Endocrinol (Lausanne). 2014; 5:128. doi: 10.3389/fendo.2014.00128.

40. Chen G, Wang D, Vikramadithyan R, Yagyu H, Saxena U, Pillarisetti S, et al. Inflammatory cytokines and fatty acids regulate endothelial cell heparanase expression. Biochemistry. 2004; 43(17):4971-4977.

41.Han J, Woytowich AE, Mandal AK, Hiebert LM. Heparanase upregulation in high glucose-treated endothelial cells is prevented by insulin and heparin. Exp Biol Med (Maywood). 2007; 232(7):927-934.

42. Ray J, Gage FH. Differential properties of adult rat and mouse brainderived neural stem/progenitor cells. Mol Cell Neurosci. 2006; 31(3):560-573.

43. Mellough CB, Cho S, Wood A, Przyborski S. Neurite formation by neurons derived from adult rat hippocampal progenitor cells is susceptible to myelin inhibition. Neurochem Int. 2011; 59(3):333340. doi: 10.1016/j.neuint.2011.01.015.

44. Webber AP, Martin JL, Harker JO, Josephson KR, Rubenstein LZ, Alessi CA. Depression in older patients admitted for postacute nursing home rehabilitation. J Am Geriatr Soc. 2005; 53(6):1017-1022.

45. Piatti VC, Ewell LA, Jill K. Leutgeb JK. Neurogenesis in the dentate gyrus: carrying the message or dictating the tone. Front Neurosci. 2013; 7:50. doi: 10.3389/fnins.2013.00050. 